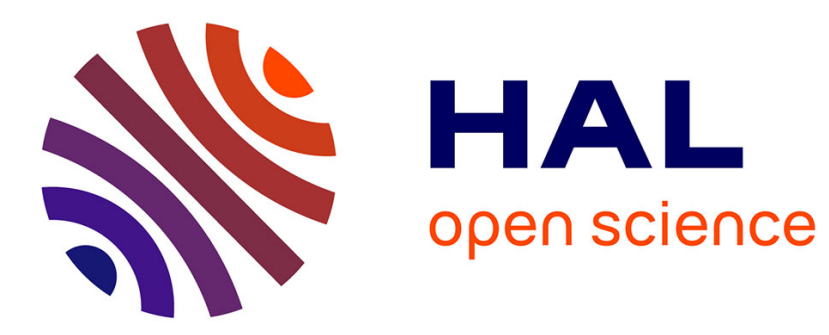

\title{
Electrostatic analysis of backscattered heavy ions for semiconductor surface investigation
}

\author{
M. Hage-Ali, P. Siffert
}

\section{To cite this version:}

M. Hage-Ali, P. Siffert. Electrostatic analysis of backscattered heavy ions for semiconductor surface investigation. Revue de Physique Appliquée, 1981, 16 (4), pp.165-172. 10.1051/rphysap:01981001604016500 . jpa-00244909

\section{HAL Id: jpa-00244909 https://hal.science/jpa-00244909}

Submitted on 1 Jan 1981

HAL is a multi-disciplinary open access archive for the deposit and dissemination of scientific research documents, whether they are published or not. The documents may come from teaching and research institutions in France or abroad, or from public or private research centers.
L'archive ouverte pluridisciplinaire HAL, est destinée au dépôt et à la diffusion de documents scientifiques de niveau recherche, publiés ou non, émanant des établissements d'enseignement et de recherche français ou étrangers, des laboratoires publics ou privés. 


\title{
Electrostatic analysis of backscattered heavy ions for semiconductor surface investigation
}

\author{
M. Hage-Ali and P. Siffert \\ Centre de Recherches Nucléaires, Groupe de Physique et Applications des Semiconducteurs (PHASE), \\ 67037 Strasbourg Cedex, France.
}

(Reçu le 22 octobre 1980, révisé le 15 janvier 1981, accepté le 19 janvier 1981)

\begin{abstract}
Résumé. - Les possibilités d'analyse de surface par rétrodiffusion de particules chargées sont limitées, à l'heure actuelle, par la résolution limitée des détecteurs à semiconducteurs et par la dégradation rapide de leurs performances pour des projectiles lourds. Dans cet article, nous décrivons les possibilités offertes par un analyseur électrostatique, capable de détecter des ions lourds $\left({ }^{7} \mathrm{Li}^{+},{ }^{12} \mathrm{C}^{+}\right)$pour l'analyse des surfaces de semiconducteurs composés. Un intérêt particulier est porté aux problèmes de résolution en masse et de résolution en profondeur.

Abstract. - The capabilities of Rutherford backscattering in surface analysis are limited by the energy resolution of the solid state detectors and their rapid degradation for heavier projectiles. Here, we investigate the possibilities of an electrostatic analyser (ESA) detecting heavy projectiles $\left({ }^{7} \mathrm{Li}^{+},{ }^{12} \mathrm{C}^{+}\right)$backscattered from various compound semiconductor surfaces, essentially with respect to mass and depth resolution.
\end{abstract}

1. Introduction. - Surface analysis by means of ion beams in the $\mathrm{keV}-\mathrm{MeV}$ energy range becomes a very powerful method for investigating solids. Among the various techniques employed, Rutherford backscattering (RBS) of ${ }^{1} \mathrm{H}^{+}$or ${ }^{4} \mathrm{He}^{+}$ions in the $1-5 \mathrm{MeV}$ range, the detector being a silicon Schottky barrier, offers many advantages : non destructability, absolute concentration and location of impurities, etc. Many publications on the subject are available, especially concerning semi-conductor surfaces [1-3]. The light projectiles, mentioned above have been chosen essentially for the easy beam production in the Van de Graaff accelerator and the good detection capabilities of silicon Schottky diodes for these particles. In principle, however, heavier ions should offer several advantages [4], particularly better mass and depth resolution and high cross section. Therefore, several groups have tried to employ either ${ }^{12} \mathrm{C}^{+}$ $[5-8],{ }^{14} \mathrm{~N}^{+}[9-11],{ }^{16} \mathrm{O}^{+}$[12] or even ${ }^{7} \mathrm{Li}^{+}$[13-15] beams. But, several problems arise when solid state detectors are used with heavy ions $[16,17]$ :

- the detector degrades quickly due to the radiation damage induced in the silicon and the Schottky barrier (Fig. 1);

- the energy resolution is much poorer for heavy ions than for protons (Fig. 2) due to fluctuations in energy loss by nuclear collisions, which give no electron-hole pairs;

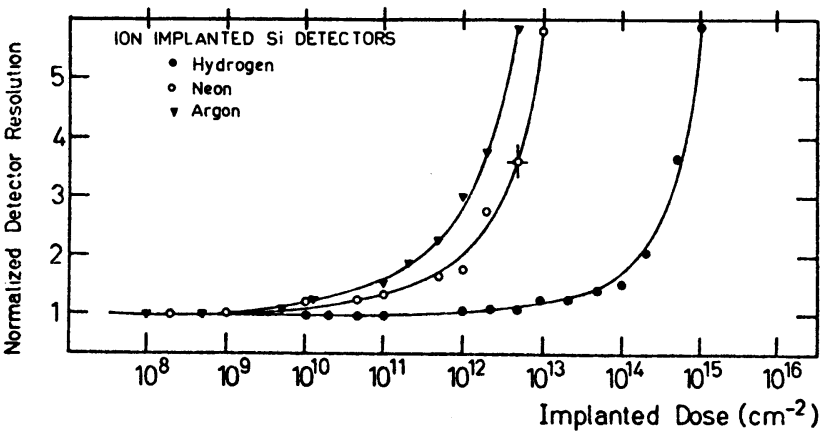

Fig. 1. - Resolution degradation of implanted silicon detectors versus various heavy ion doses [29].

- the amplitude of the signal is smaller and depends on the type of particle, because of window effect and nuclear collisions (Fig. 3).

To improve the resolution of RBS, some authors suggested the use of magnetic analysers [18-19], which are rather cumbersome systems or electrostatic analysers (ESA), which are usually limited to use with low energy ions $(<500 \mathrm{keV})[7,21,22]$.

Here, we consider the possibilities of ESA for light heavy projectiles of energies up to $1 \mathrm{MeV}$ and also the advantages attending the use of the heavier ions when the drawbacks due to other detection systems are eliminated. 


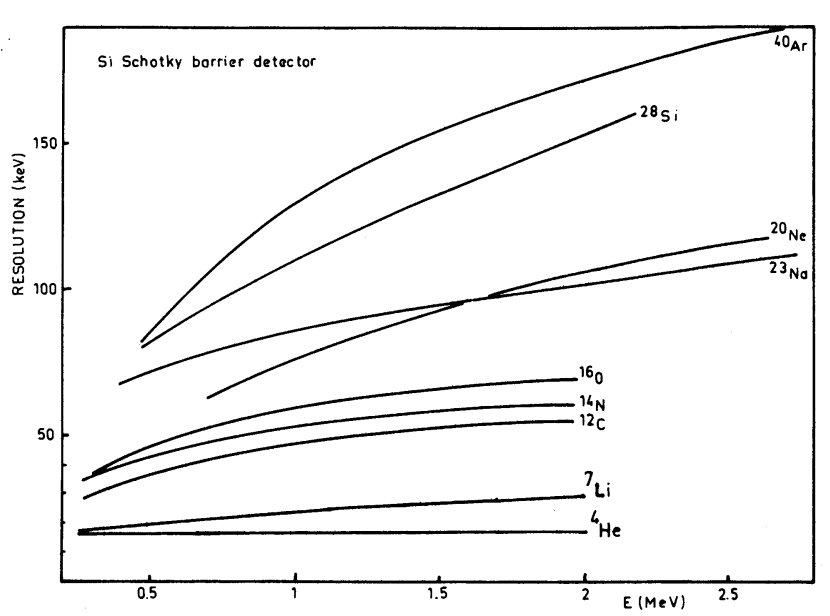

Fig. 2. - Evolution of silicon detector energy resolution with ions species as a function of energy.

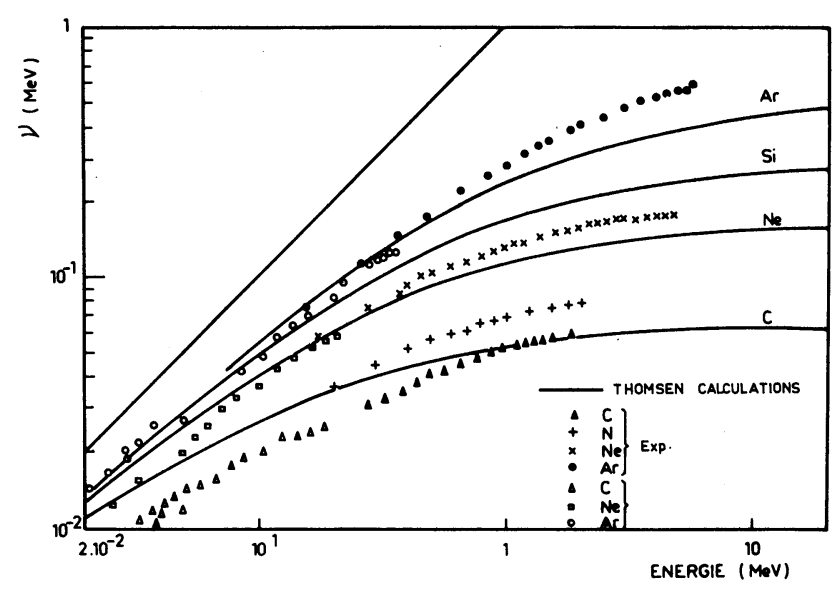

Fig. 3. - Effect of nuclear collisions on pulse amplitude delivered by a silicon detector versus energy for various heavy ions.

2. Ion scattering. -2.1 KINEMATICs. - Under the Rutherford elastic scattering collision assumption, a projectile of energy $E_{0}$ and mass $M_{1}$ scattered at a lab angle $\theta$ from an atom $M_{2}$ at rest $\left(\mu=M_{1} / M_{2}\right)$ looses part of its initial energy, such that its new value is :

$$
E=K E_{0}
$$

where the factor $K$ is expressed by :

$K(\mu, \theta)=\left\{\left[\mu \cos \theta+\left(1-\mu^{2} \sin ^{2} \theta\right)^{1 / 2}\right] /(1+\mu)\right\}^{2}$, with

$$
\sin \theta<1 / \mu .
$$

The evolution of $K$ as a function of $1 / \mu$ and $\theta$ is shown in figure 4.

RBS is, therefore, useful for mass analysis with a rather complicated conversion scale $K$, except for two angles $\theta=90$ and $180^{\circ}$, where :

$$
K_{180^{\circ}}=\left(\frac{1-\mu}{1+\mu}\right)^{2}, \quad K_{90^{\circ}}^{2}=K_{180^{\circ}}
$$

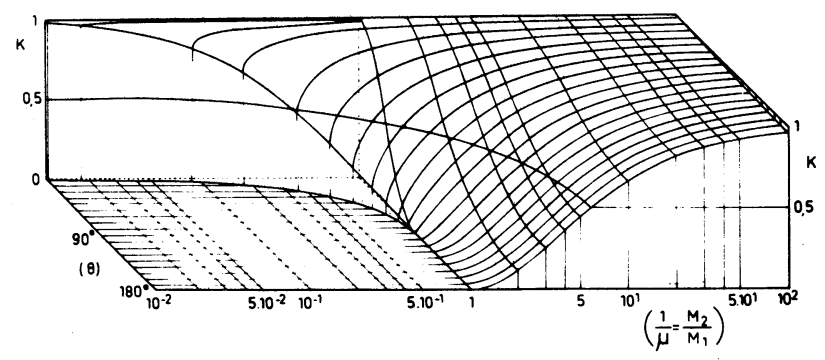

Fig. 4. - Evolution of kinematic factor $K$ versus laboratory angle $\theta$ and mass ratio $1 / \mu$.

In figure 4 we have also plotted the $K$ values for $\mu \geqslant 1$ even though this condition is generally not used in RBS, but which, nevertheless, constitues a domain of interest in some situations as will be considered later. It is interesting to notice at this point that for relative light elements, the factor $K$ is rather uniform for all $(\mu)$ values, leading to a rather poor mass resolution. For heavy projectiles, $K$ changes more drastically, especially for particular $(\theta)$ and $(\mu)$ values. It is, therefore interesting to evaluate the mass resolution.

2.2 Mass Resolution IN RBS. - Let us establish the relationship existing between the energy resolution $\Delta E$ and the mass resolution $\Delta M_{2}$.

By differentiating equation (1) we can write :

$$
\Delta E=\Delta K \cdot E_{0}=\frac{\Delta K}{\Delta \mu} \frac{\Delta \mu}{\Delta M_{2}} \Delta M_{2} \cdot E_{0} .
$$

From equation (2), we have :

$$
\frac{\Delta K}{\Delta \mu}=\frac{-2\left[\left(1-\mu^{2} \sin ^{2} \theta\right)^{1 / 2}+\mu \cos \theta\right]\left\{1+\mu-\cos \theta\left[\left(1-\mu^{2} \sin ^{2} \theta\right)^{1 / 2}+\mu \cos \theta\right]\right\}}{(1+\mu)^{3}\left(1-\mu^{2} \sin ^{2} \theta\right)^{1 / 2}},
$$

and

$$
\frac{\Delta \mu}{\Delta M_{2}}=-\frac{\mu}{M_{2}} \text {. }
$$

Combining equations (5-7), equation (5) becomes :

$$
\Delta E=\left(\frac{\Delta K}{\Delta \mu}\right)\left(-\frac{\mu}{M_{2}}\right) \Delta M_{2} \cdot E_{0}
$$


and

$$
\frac{M_{2}}{\Delta M_{2}}=\frac{E_{0}}{\Delta E} \times \frac{2 \mu\left(1-\mu^{2} \sin ^{2} \theta\right)^{1 / 2}}{(1+\mu)^{3}\left(1-\mu^{2} \sin ^{2} \theta\right)^{1 / 2}}\left\{1+\mu-\cos \theta\left[\left(1-\mu^{2} \sin ^{2} \theta\right)^{1 / 2}+\mu \cos \theta\right]\right\} .
$$
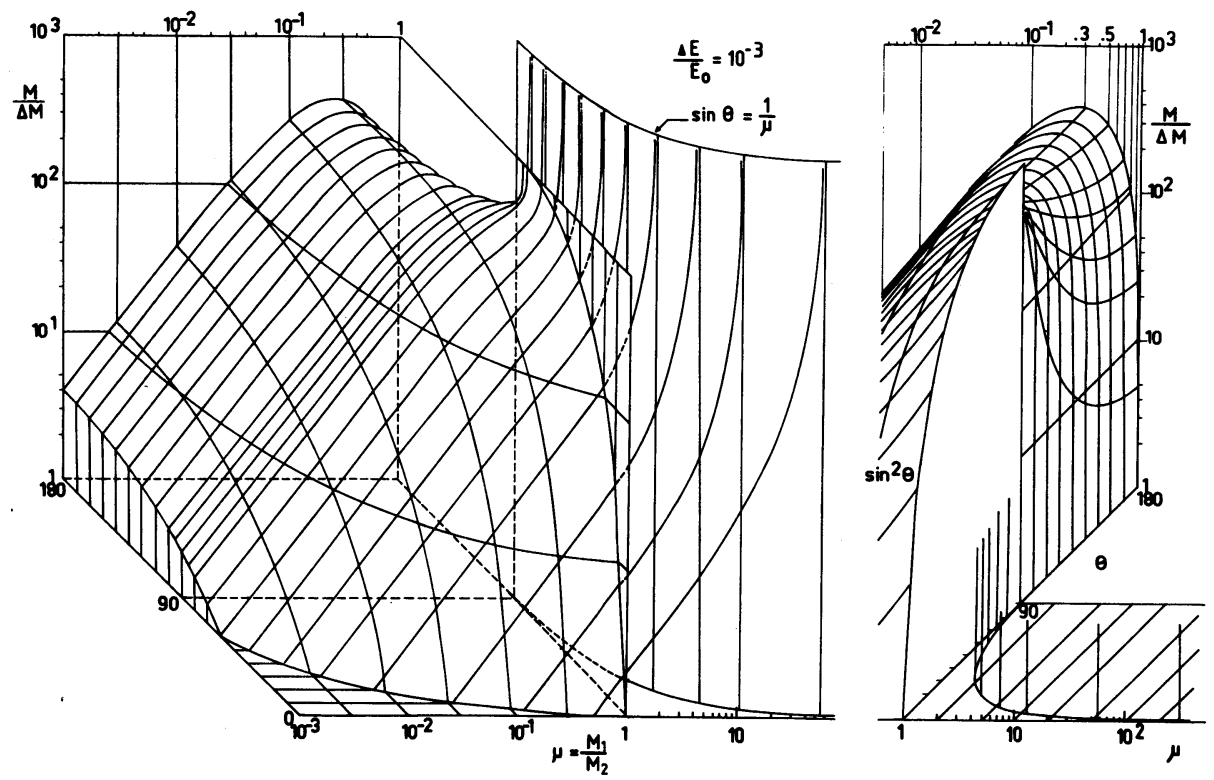

Fig. 5. - Evolution of the resolution in mass $M_{2} / \Delta M_{2}$ as a function of angle $\theta$ mass ratio $\mu$ for $\Delta E / E=10^{-3}$, with extension to $M_{1}>M_{2}$.

Figure 5 gives the evolution of mass resolution versus $\theta$ and $\mu$ for a relative resolution in energy $\Delta E / E_{0}=10^{-3}$. It should be pointed out that the maximum in mass resolution increases from 380 to 1000 when $\mu$ increases from 0.26 to 1 and $\theta$ varies from 180 to $90^{\circ}$ : for $\mu \geqslant 1$ and $0^{\circ}<\theta<90^{\circ}$, $M_{2} / \Delta M_{2}$ reaches very high values, going to $\infty$ for $\theta=\arcsin 1 / \mu$. As mentioned above, these conditions are not used in RBS today.

The backscattering cross section, expressed by :

$$
\begin{aligned}
\frac{\mathrm{d} \sigma}{\mathrm{d} \Omega}=\left(\frac{Z_{1} Z_{2} e^{2}}{4 E_{0}}\right)^{2} \frac{4}{\sin ^{4} \theta} \times \\
\times \frac{\left[\left(1-\mu^{2} \sin ^{2} \theta\right)^{1 / 2}+\cos \theta\right]^{2}}{\left(1-\mu^{2} \sin ^{2} \theta\right)^{1 / 2}},
\end{aligned}
$$

its variation is shown on figure 6. It appears, in particular, that the angles between 0 and $90^{\circ}$, together with a value of $\mu$ close to unity are still better than an angle of $180^{\circ}$.

A specific example, perhaps, shows the improvement better : from figure 7 it appears that for $M_{2}=70$ (gallium), $\theta=150^{\circ}, \Delta E / E_{0}=4 \%, M_{2} / \Delta M_{2}$ increases from 43 with' ${ }^{4} \mathrm{He}^{+} \cdot\left(\Delta M_{2}=1.6\right)$ to 98 for a ${ }^{12} \mathrm{C}^{+}$beam $\left(\Delta M_{2}=0.7\right)$ and $\Delta M_{2}$ reaches even 6 for ${ }^{4} \mathrm{He}^{+}$ion and a conventional surface barrier detector $\left(\Delta E / E_{0}=1.7 \%\right)$. (8) :

Further conclusion can be drawn from equation

- the impinging beam should have as high as possible energy $E_{0}$,

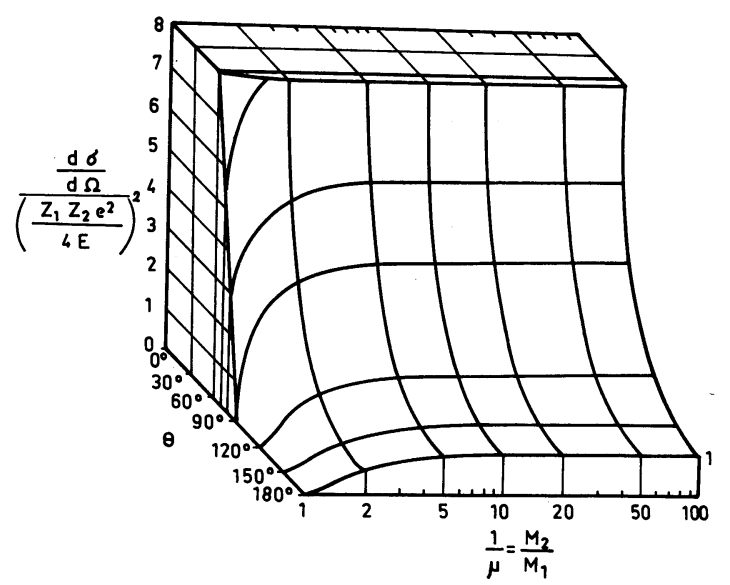

Fig. 6. - Evolution of the relative backscattering cross-section versus $\theta$ and $\mu$.

- the resolution $\Delta E$ should be the best. It should be mentioned that a few hundred $\mathrm{eV}$ beam energy dispersion are attainable today [23] with Van de Graaff accelerators. Ideally, a detection system should be able to measure this, which, of course, is not the case with solid state detectors, as indicated above.

3. Depth resolution in RBS. - For an energy resolution $\Delta E$, the depth resolution $\Delta D / D$ can be calculated by considering figure 8

$\Delta E=E_{0}-E=\left(\frac{K}{\cos \theta_{1}} S_{1}+\frac{1}{\cos \theta_{2}} S_{2}\right) D$ 
in which $S_{1}$ and $S_{2}$ are the energy loss of the projectile in the impinging and backscattered direction. To simplify, we can choose a mean energy loss $S$ such that :

and

$$
\Delta E \simeq E_{0}-E=\left(K-\frac{1}{\cos \theta}\right) \bar{S} D,
$$

$$
\begin{gathered}
\frac{D}{\Delta D}=\frac{\left(K-\frac{1}{\cos \theta}\right) \bar{S} D}{\Delta E}, \\
\frac{D}{\Delta D}=\left\{\left[\frac{\mu \cos \theta+\left(1-\mu^{2} \sin ^{2} \theta\right)^{1 / 2}}{1+\mu}\right]^{2}-\frac{1}{\cos \theta}\right\}\left(\frac{\bar{S} D}{\Delta E}\right) .
\end{gathered}
$$

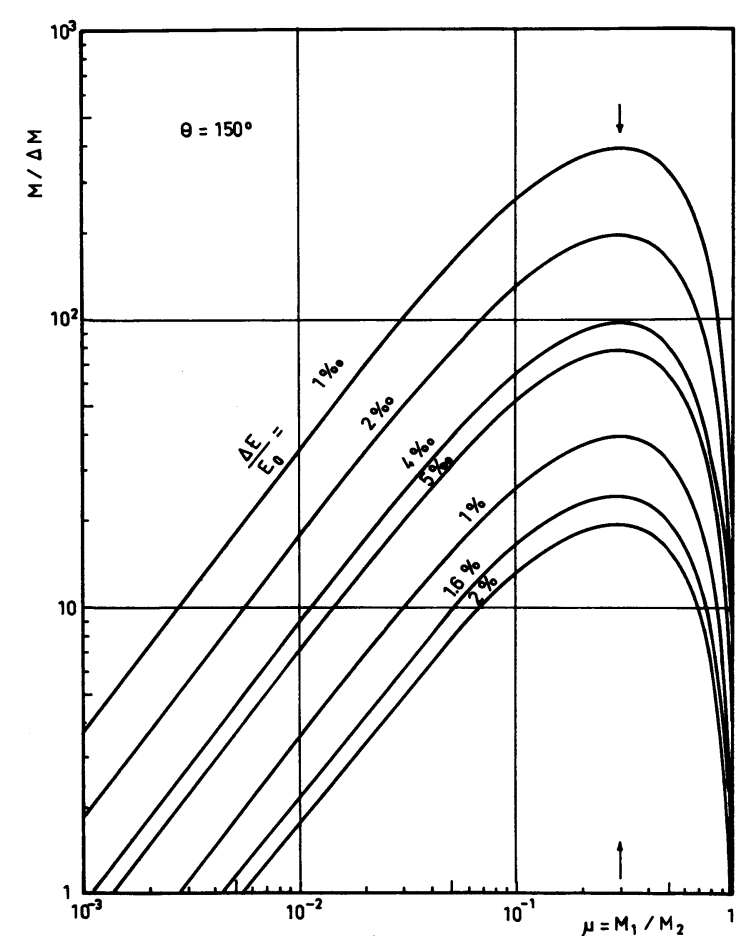

Fig. 7. - Evolution of mass resolution $M_{2} / \Delta M_{2}$ as a function of ratio $\mu$ and energy resolution $\Delta E / E_{0}$ for an angle $\theta=150^{\circ}$. Notice the progress when going from Schottky silicon detector (resolution $2 \%$ ) to the electrostatic system (resolution $4 \%$ ).

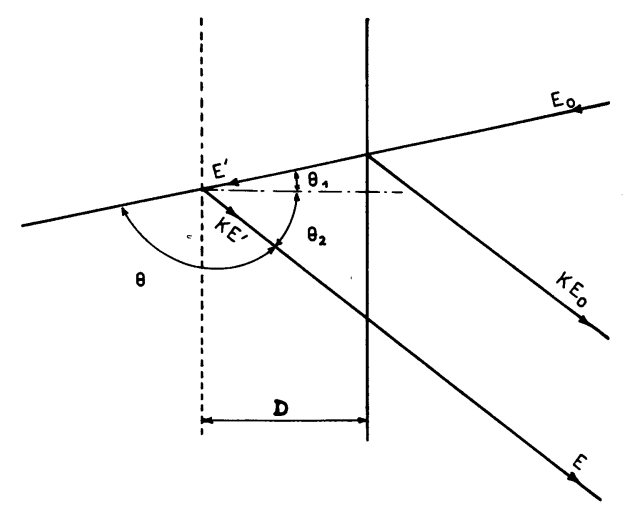

Fig. 8. - Principle of backscattering analysis.

As we did previously for the mass resolution, we report on figure 9 the evolution of depth resolution

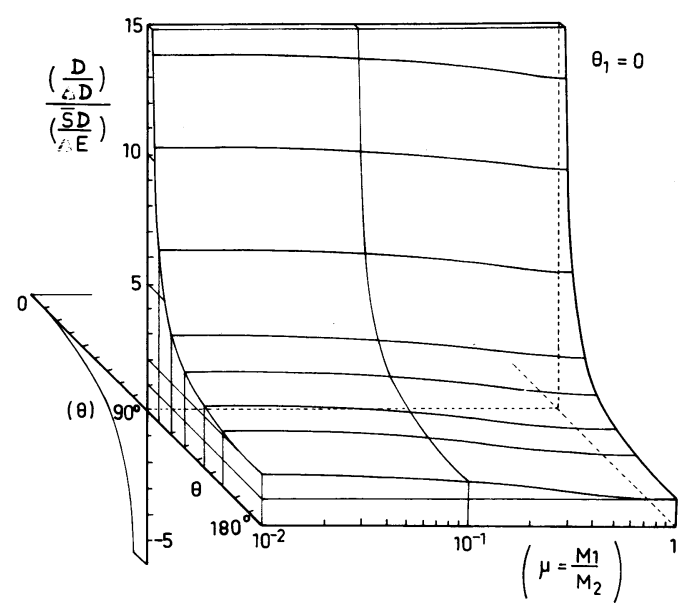

Fig. 9. - Evolution of depth resolution versus $\theta$ and $\mu$.

versus $\theta$ and $\mu$. When going from light to heavy projectiles, the kinematics depth resolution degrades at least a factor of two at $\theta=180^{\circ}$, for $\mu$ going from 10 to $\mu=1$ but in reality, this value must be multiplied by the stopping power $\bar{S}$ and divided by the energy resolution. The optimum depth resolution is, therefore, achieved when the following conditions are fullfiled :

- a good energy resolution $\Delta E$;

- as large a thickness $D$ as possible. This can be artificially obtained by using glancing angle geometry ;

- use of particules and energy $E_{0}$ corresponding to the maximum stopping power $\bar{S}$. This maximum starts around $100 \mathrm{keV}$ for ${ }^{1} \mathrm{H}^{+}$and increases with the mass of the projectile (Fig. 10) being around $3 \mathrm{MeV}$ for ${ }^{12} \mathrm{C}^{+}$. It is, therefore, advantageous to use an ESA operating at high energy. $\bar{S}$ increases from $5 \mathrm{eV} / \AA$ for ${ }^{1} \mathrm{H}^{+}$to $30 \mathrm{eV} / \AA$ for ${ }^{4} \mathrm{He}^{+}$and $120 \mathrm{eV} / \AA$ for ${ }^{12} \mathrm{C}^{+}$, in $\mathrm{Al}$, all projectiles having $1 \mathrm{MeV}$ energy. This value is even higher, by a factor $2-3$, for heavy targets like $\mathrm{Au}$ or $\mathrm{Ni}$;

- reduction in the energy straggling [20]. The energy fluctuation of the machine must be as small as possible. However, after a penetration of about $1000 \AA$, the beam straggling becomes equivalent to the resolution of a solid state detector; therefore, 


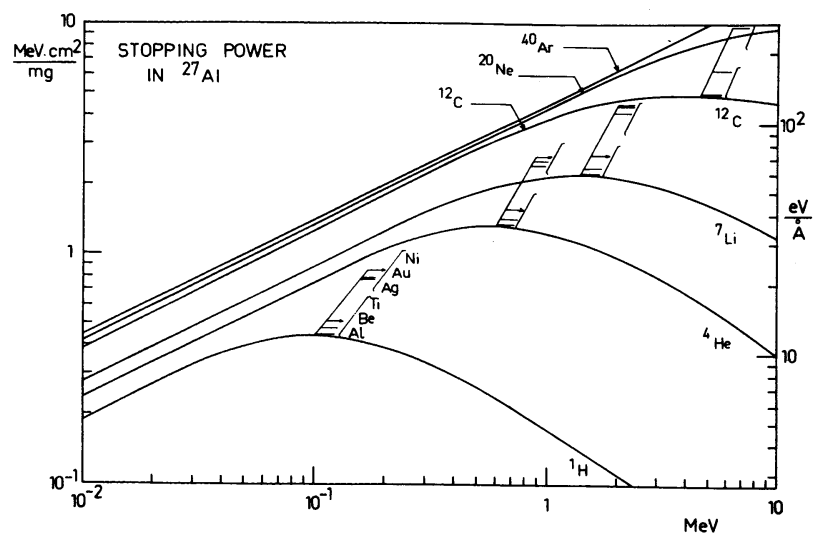

Fig. 10. - Stopping power of various ions in aluminium, arrows and brackets give maximum stopping power for some heavier targets ( $\mathrm{Be}, \mathrm{Ti}, \mathrm{Ag}, \mathrm{Au}, \mathrm{Ni}$ ) expressed in $\mathrm{eV} / \AA$.

sophisticated ESA is really of full use in investigating close surface layers.

4. The electrostatic analyser (ESA). - The principle and practical realization of our ESA, which operates up to $1 \mathrm{MeV}$ for all particles have been published elsewhere [20]. For theory see references [24-26]. Here we restrict ourself to figures 11 and 12 showing the schematic of the system.

5. Results. - As previously indicated, an ESA system using heavy ions in the $\mathrm{MeV}$ range is best suited for near surface analysis, at depths in the order of about $1000 \AA$. The depth resolution capabilities are illustrated by the figures $13 a$ and $b$ for thin gold layers deposited on silicon and analysed, respectively by a conventional surface barrier detector and ESA. It should be noticed on figure $13 a$ that the depth

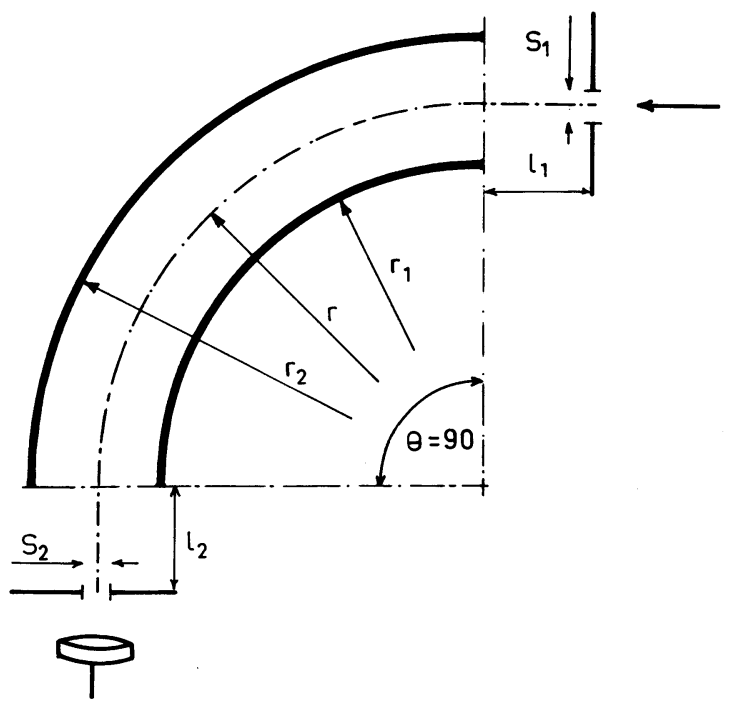

Fig. 11. - Schematic drawing of our electrostatic analyser.

resolution degrades quickly with penetration of the projectile in the film, due to the beam straggling.

The high mass resolution allows the determination of the surface stoichiometry of compound semiconductors : depending on the mass resolution and the nature of the projectile, the theoretical spectra, taking into account the various isotopes of $\mathrm{GaAs}$ and CdTe are shown on figures 14 and 15. The experimental spectra depend also on crystal quality and real stoichiometry; some results are reported on figures 16 to 19 for cleaved surfaces, first analysed. with light projectiles and then with ${ }^{7} \mathrm{Li}^{+}$and ${ }^{12} \mathrm{C}^{+}$ beams. For GaAs, the mass resolution improves from 1.7 for ${ }^{4} \mathrm{He}^{+}$to 1.4 for ${ }^{7} \mathrm{Li}^{+}$and even 0.8 for ${ }^{12} \mathrm{C}^{+}$. In the case of $\mathrm{CdTe}$, the values improve from 5 to 2.0 for the same projectiles. In the case of a

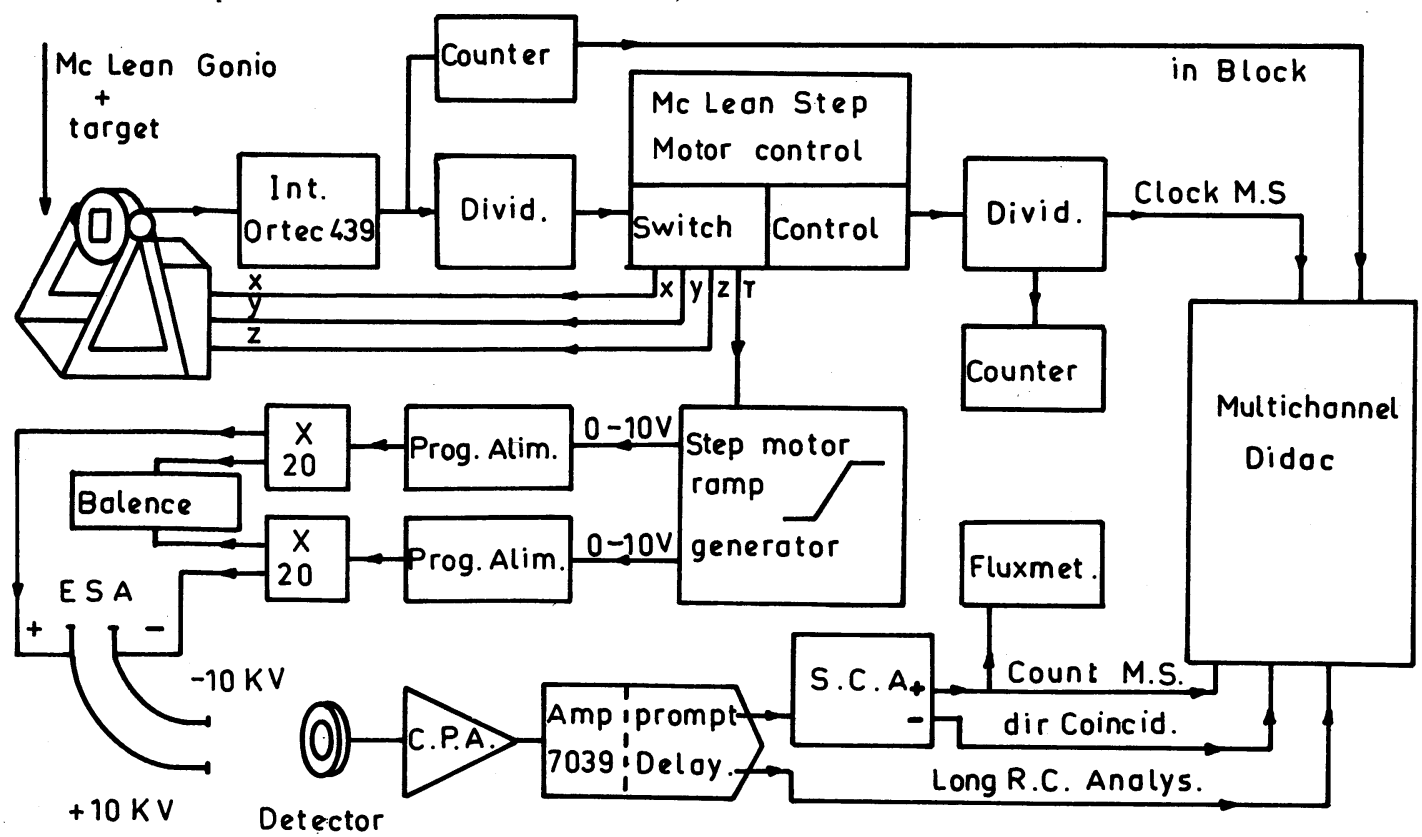

Fig. 12. - Electronic set-up used in ESA analysis system. 


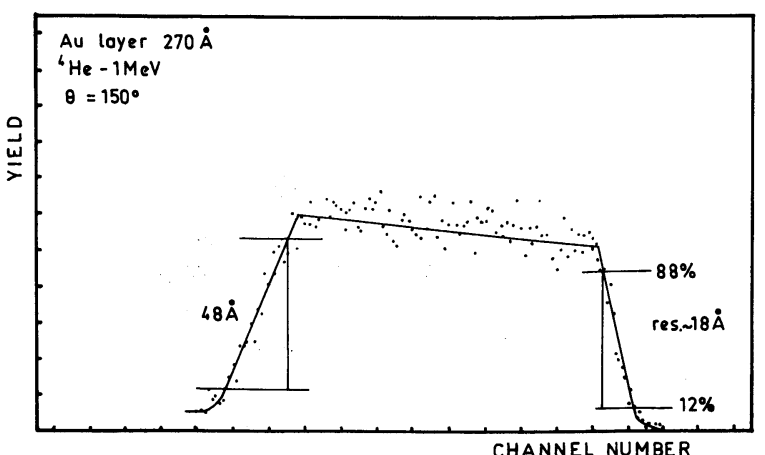

a)

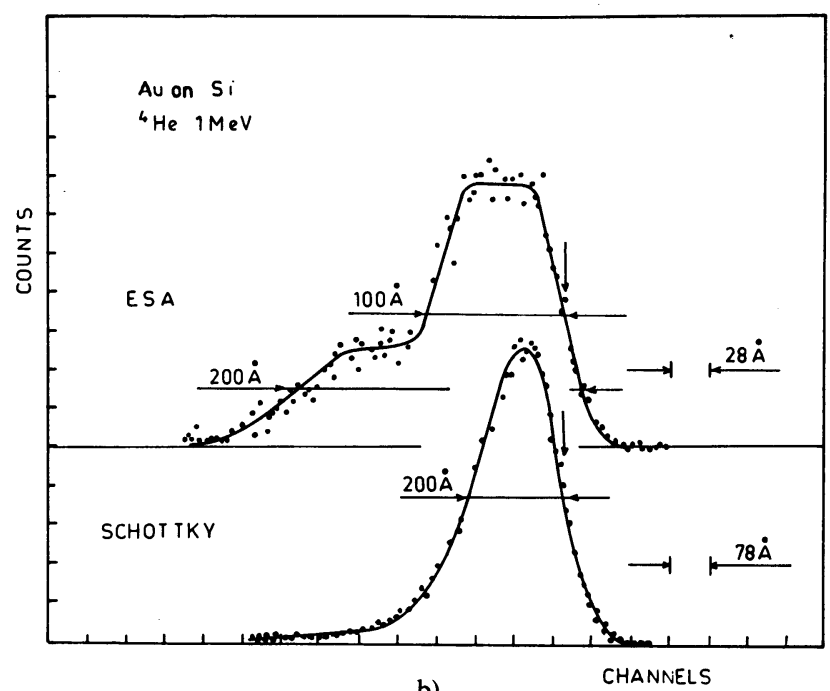

b)

Fig. 13. - (a) ESA analysis of a gold layer $270 \AA$ thick, showing the surface and depth resolution. (b) Comparison of ESA and Schottky barrier detector performance in analysing a diffused gold layer into silicon.

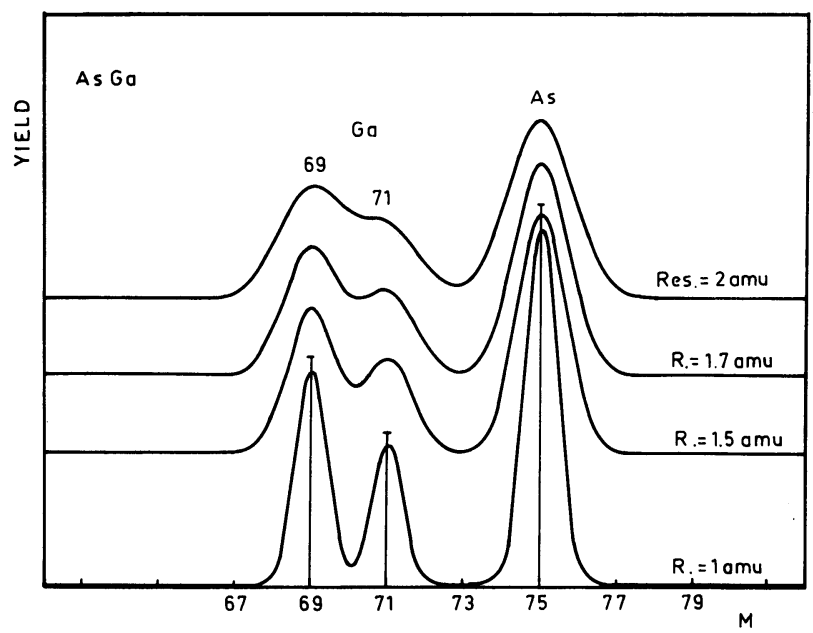

Fig. 14. - Calculated surface spectrum of AsGa as seen by backscattering under channelling conditions for various mass resolutions.

conventional Schottky barrier, having a resolution of $16 \mathrm{keV}$, the mass resolution would become 17 .

When channelling conditions are requested, the use of heavy ions constitutes a further advantage,

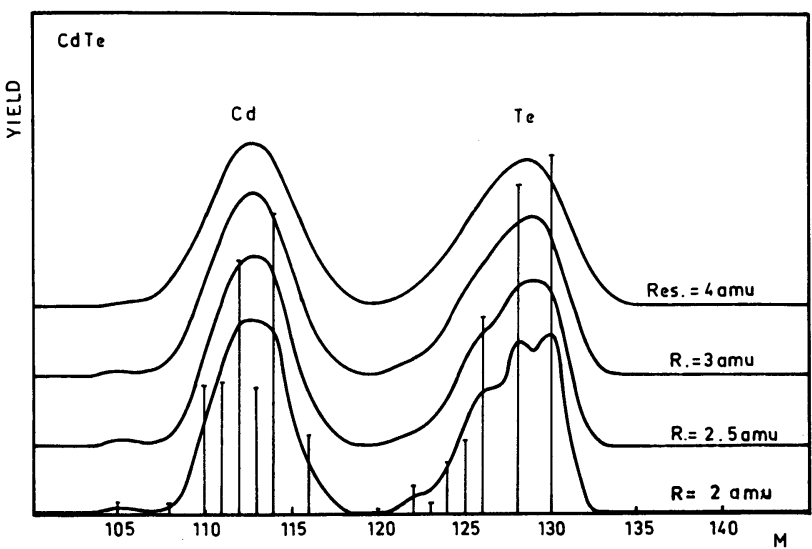

Fig. 15. - Calculated surface spectrum of CdTe as seen by backscattering under channelling conditions for various mass resolutions.

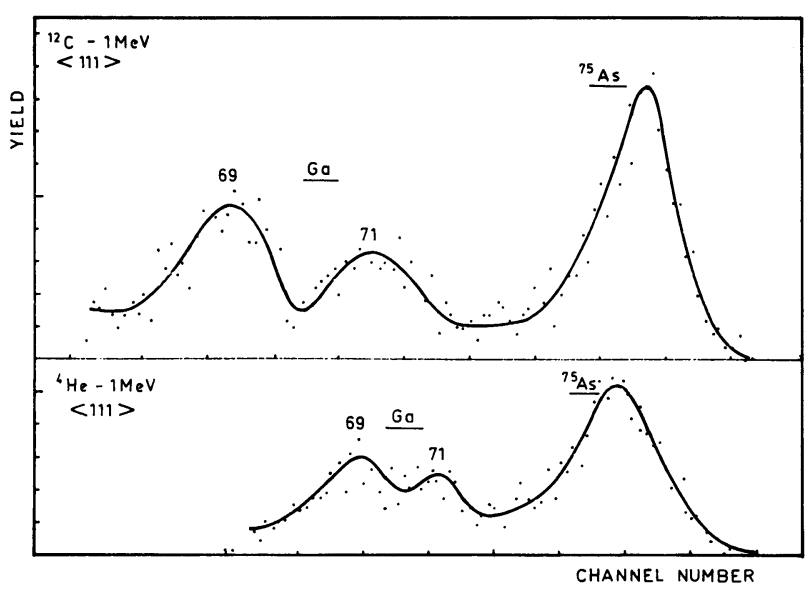

Fig. 16.

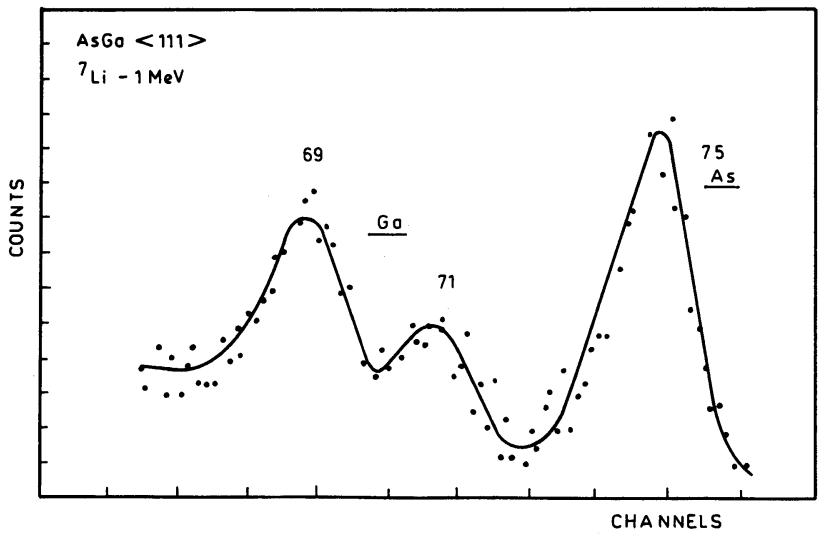

Fig. 17.

Figs. 16-17. - Experimental spectra obtained on GaAs observed by backscattering with $1 \mathrm{MeV}{ }^{12} \mathrm{C}^{+},{ }^{4} \mathrm{He}^{+},{ }^{7} \mathrm{Li}^{+}$ions.

since the critical angle becomes larger, as shown on figure 20 for CdTe, investigated by means of a ${ }^{7} \mathrm{Li}^{+}$ beam. The expected theoretical values $[27,28]$ are also reported. However, it should be noticed, as already indicated, that for some crystals the alignement is still difficult when compound semiconductors are used, due to non perfect crystal structure. Fur- 


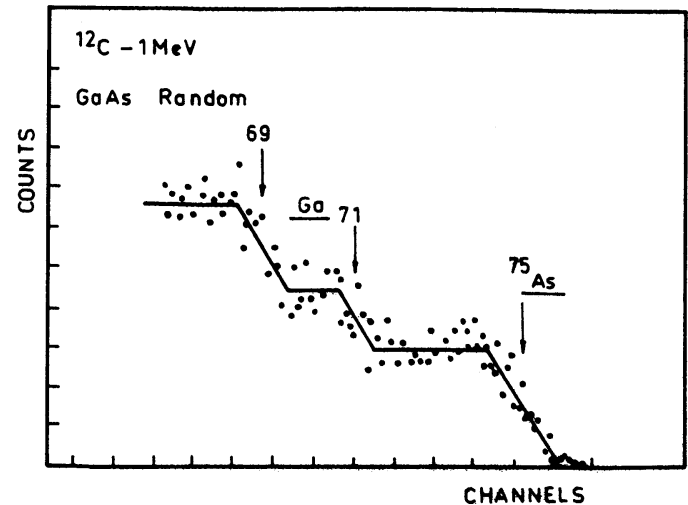

Fig. 18. - Backscattering spectrum obtained with ${ }^{12} \mathrm{C}^{+}$ions impinging under random incidence on GaAs.

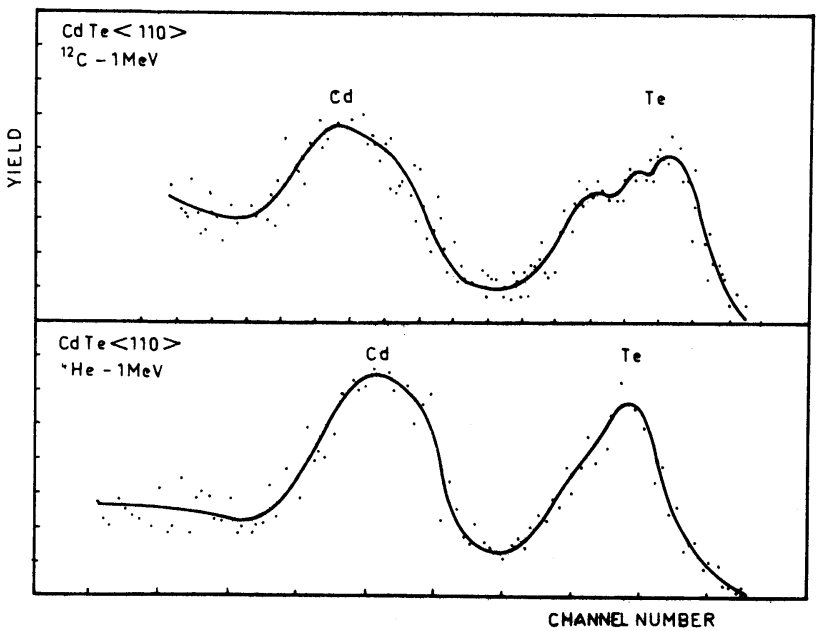

Fig. 19. - Surface analysis of CdTe under channelling conditions as seen with $1 \mathrm{MeV}^{12} \mathrm{C}^{+}$and ${ }^{4} \mathrm{He}^{+}$projectiles.

thermore, care must also be given to the eventual radiation damage created on the material by the analysing heavy projectiles : in some of our experi-

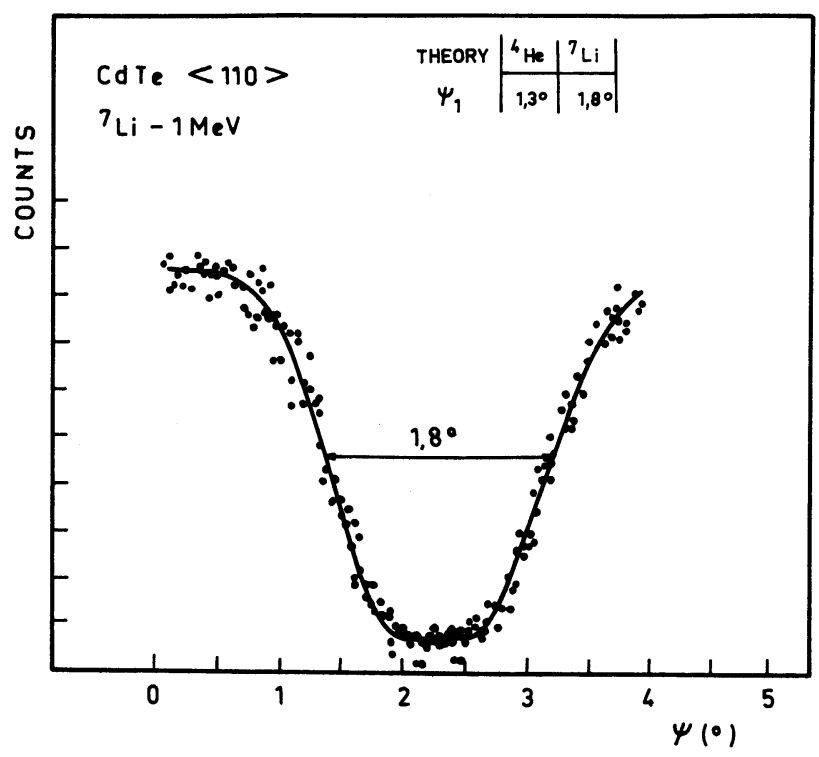

Fig. 20. - Angular scanning of an $\langle 110\rangle$ axis of CdTe as seen by $1 \mathrm{MeV}{ }^{7} \mathrm{Li}^{+}$ions.

ments, the target was moved during the beam analysis, which needs very good mechanical alignement of the whole goniometer set-up.

6. Conclusion. - The combination of ESA and heavy projectiles open new possibilities of RBS in surface analysis. In fact, both depth and mass resolution can be enhanced. Besides the stoichiometry measurements, we have shown that this procedure is also of importance for heavy ions diffusion experiments as well as range of particles in light targets $[14,21]$. The main drawback of this technique is related to the very long counting rate, of several hours per spectrum, for low cross section elements. In this case, care must be devoted to the damage resulting from the analysing beam itself.

\section{References}

[1] MAYER, J. W., Ion implantation in semiconductors (Academic Press, New York) 1970.

[2] CROWDER, B. L., Ion Implantation in Semiconductors and Other Materials (Plenum Press, New York) 1973.

[3] Chu, W. K., MAYER, J. W. and Nicolet, M. A., Backscattering Spectrometry (Academic Press, New York) 1978.

[4] MAYeR, J. W., ERIKsson, L., Davies, J. A., Ion Implantation in Semiconductors (Academic Press, London) 1970, p. 143.

[5] Feldmann, L. C., Kaufmann, E. N., Mingay, J. W., AugusTYNIAK, W. M., Phys. Rev. Lett. 27 (1971) 1145.

[6] Ericksson, L., Fladda, G., Björkqvist, K., Appl. Phys. Lett. 14 (1969) 195.

[7] Bergstrom, I., Björkvist, K., Dameï, B., Fladda, G., Can. J. Phys. 46 (1968) 2679.

[8] Abel, F., Amsel, G., Bruneaux, M., Cohen, C., Maurel, B., Rigo, S., Roussel, J., J. Radioamal. Chem. 16 (1973) 587.
[9] Feldman, L. C., Murnick, D. E., Phys. Rev. B 5 (1972) 1. [10] Alexander, R. B., Ph. D. Thesis, Oxford (1971) AERE Report 6849.

[11] BфGH, E., Proc. Roy. Soc. A 311 (1969) 35.

[12] Ref. [4], p. 145.

[13] Thomas, J. P., Cachard, A., Fallavier, M., Tardy, I., Marsaud, S. et Pivot, J., Revue Phys. Appl. 11 (1976) 65.

[14] Id. ion beam surface Layer analysis, Meyer, Linker, Käppeler (Plenum Press) 1976, p. 425.

[15] L'Ecuyer, J., Brassard, C., Cardinal, C., Deschene, L. JUtras, Y., LABRIE, J. P., Nucl. Instrum. Methods $\mathbf{1 4 0}$ (1977) 305.

[16] Grob, A., Grob, J. J., Siffert, P., Nucl. Instrum. Methods 132 (1976) 273.

[17] GroB, J. J., Thesis Université de Strasbourg (1979) (Fig. 44).

[18] Hirvonen, J. K., Hubler, G. K., référence [14], p. 457. 
[19] В $\emptyset \mathrm{GH}$, E., Radiat. Eff. 12 (1972) 13.

[20] Hage-Ali, M., Siffert, P., Nucl. Instrum. Methods 166 (1979) 411.

[21] Wijngaarden, A. V., Miranadi, B., Baylis, W., Can. J. Phys. 49 (1971) 2440.

[22] Feuerstein, A., Grahmann, H., Kalbitzer, S. and OetzMANN, H., reference [14], page 471.

[23] Amsel, G., Nadai, J. P., D’Artemare, E., David, D., Girard, E., MoulaIN, J., Nucl. Instrum. Methods 92 (1971) 481.
[24] Durand, E., Electrostatique Tome II (éd. Masson, Paris) 1966.

[25] JAYARAM, R., Mass spectrometry (Plenum Press, New York) 1966, p. 22.

[26] McDowell, C. A., Mass spectrometry (McGraw-Hill, New York) 1963, p. 151.

[27] MaYeR, J. W., Rimini, E., Ion Beam Handbook for Material Analysis (Academic Press, New York) 1977, p. 71.

[28] Grob, J. J., Thesis 3e cycle, page 11, Strasbourg (1973).

[29] Kalbitzer, S., Private communication. 